\title{
Prognostic impact of serum and tissue MMP-9 in non-small cell lung cancer: a systematic review and meta-analysis
}

\author{
Liang Gong ${ }^{1, *}$, Dan $\mathbf{W u}^{2, *}$, Jianding Zou ${ }^{1}$, Jianqiang Chen ${ }^{1}$, Liangyu Chen ${ }^{1}$, Yun \\ Chen ${ }^{3}$, Chao $\mathrm{Ni}^{4}$, Hongjun Yuan ${ }^{4}$ \\ ${ }^{1}$ Department of Otorhinolaryngology, Affiliated Cixi Hospital of Wenzhou Medical University, Cixi 315300, China \\ ${ }^{2}$ Department of Thoracic surgery, Affiliated Cixi Hospital of Wenzhou Medical University, Cixi 315300, China \\ ${ }^{3}$ Department of Oncology, Zhejiang Provincial People's Hospital, Hangzhou 310004, China \\ ${ }^{4}$ Department of General Surgery, Zhejiang Provincial People's Hospital, Hangzhou 310004, China \\ *Co-first author \\ Correspondence to: Hongjun Yuan, e-mail: yuanhongjunqq@126.com \\ Chao Ni,e-mail: davenc@163.com \\ Keywords: matrix metalloprotease-9, non-small cell lung cancer, immunohistochemistry, ELISA \\ Received: December 07, $2015 \quad$ Accepted: February 14, $2016 \quad$ Published: February 23, 2016
}

\section{ABSTRACT}

Matrix metalloproteinases-9 (MMP-9) was one of the most important enzyme to breakdown extracellular matrix, aim to clarify the prognostic value of MMP-9 in non-small cell lung cancer (NSCLC), we investigated the serum MMP-9 of NSCLC patients and performed a meta-analysis of the published literature. The expression and activity of serum MMP-9 were assessed by ELISA and gelatin zymography in 163 NSCLC patients. Moreover, 26 studies were included in meta-analysis by searching Medline and ISI Web of Knowledge. Our own data revealed high activity but not expression of MMP-9 significantly correlated with advanced $T$ category and positive metastasis. In contrast, the meta-analysis revealed that increased MMP-9 level

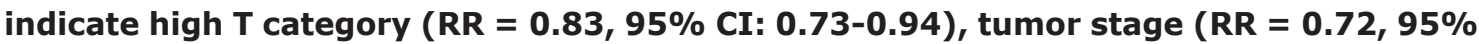
CI: $0.63-0.82$ ) and poor OS (5-year overall survival, $R R=1.32,95 \%$ CI: 1.19-1.48). Moreover, stratified analysis based on sample types found that high MMP-9 expression in tissue specimen but not serum was significant correlated with advanced $\mathrm{T}$ category $(R R=0.81,95 \% \mathrm{CI}: 0.72-0.92)$, tumor stage $(\mathrm{RR}=0.69,95 \% \mathrm{CI}: 0.60-0.80)$ and poor 5-year OS (1.33, 95\% CI: 1.18-1.50).In conclusion, the activity of MMP-9 was positively correlated with advanced $\mathrm{T}$ category and distant metastasis. Moreover, the meta-analysis revealed that overexpression of MMP-9 in tissue but not in serum was a risk factor of advanced $\mathrm{T}$ category, tumor stage and poor outcome.

\section{INTRODUCTION}

Despite improvements in diagnostic and therapeutic strategies, non-small cell lung cancer (NSCLC) still remains the most lethal malignancy worldwide. The 5 -year survival rate is only $15 \%$ overall in patients and $50-60 \%$ in resectable patients [1]. These results also revealed invasion and metastasis as the main causes of recurrence and death in lung cancer.

Numerous studies have found that the degradation of the extracellular matrix (ECM) induced by certain enzymes plays a central role in tumor metastasis. The matrix metalloproteinases (MMPs) family comprises 24 zinc dependent endopeptidases with various enzymatic activities to break down ECM. MMP-9 is part of the MMPs family and is the most important component in cancer tissue remodeling, able to catalyze types V,VII, IX, X, and IV collagen, elastin, fibrin, fibrinogen and plasminogen to facilitate malignant cell invasion and metastasis [2]. Moreover, the inhibition of MMP-9 was reported to attenuate the invasion of tumor cells [3, 4], which indicated its potential as both a cancer marker and therapeutic target. Based on the above evidence, the increased expression of MMP-9 should correlate with poor prognosis and advanced tumor stage, theoretically. However, MMP-9 has been evaluated in various human specimens, such as serum and tissue, and several studies found that high MMP-9 expression was not correlated 
with unfavorable clinicopathological features or poor prognosis, especially when evaluated in patient serum, which may be due to a small sample size in individual studies [5-8].

In this study, we examined MMP-9 expression and activity in the serum of 163 NSCLC patients by enzyme-linked immunosorbent assay (ELISA) and gelatin zymography, which provided the largest current sample size. Moreover, because MMP-9 was most frequently assessed in tumor specimens, we also performed a systematic review of published research to clarify the prognostic significance of MMP-9 in tissue and serum, and other clinicopathological features were also examined in this study.

\section{RESULTS}

\section{Patient characteristics}

A total of 163 specimens of NSCLC patients (from April 2006 to March 2011) from Wenzhou Medical college affiliated Cixi People's hospital with complete follow-up were retrospectively studied. All of the patients' pathological and demographic characteristics are shown in Supplementary Table S1. The predominant histological type of NSCLC was adenocarcinoma (79 patients, 48.5\%), followed by squamous cell carcinoma (76 patients, $46.6 \%$ ) and large cell carcinoma (8 patients, $4.9 \%$ ). At the time of diagnosis, $71(43.6 \%)$ patients had early stage disease (stage I/II), 37 (22.7\%) patients had locally advanced tumors (stage III) and 55 (33.7\%) patients had metastatic disease (stage IV).

\section{Expression and activity of MMP-9 in serum}

The mean serum level of MMP-9 in NSCLC patients was $67.08 \pm 39.57 \mathrm{ng} / \mathrm{ml}$, and the association between MMP-9 level and activity with pathological parameters was shown in Table 1. Although we found that patients with a higher MMP-9 concentration are more inclined to have an advanced clinicopathological feature $(\mathrm{N}$ and $\mathrm{M}$ stage) and worse prognosis, none of these factors reached statistical significance (Table 1, Supplementary Figure S3). Alternatively, the activity of MMP-9 was significantly correlated with advanced $\mathrm{T}$ category and positive metastasis (Table 1, Supplementary Figure S1).

\section{Search results}

Because several studies indicated that MMP-9 level could be applied as a prognostic marker in NSCLC patients, either in serum or tissue specimens, here we performed a meta-analysis with comprehensive research of the published literature. Initially, 223 publications were retrieved by our primary research. Thereafter, 160 studies were excluded based on abstracts due to either a focus on
non-NSCLC, basic research studies, reviews or written in a language other than English or Chinese. Then, the fulltexts of the remaining 63 studies were carefully reviewed. Thirty-seven studies were excluded because they did not provide a defined cut-off of MMP-9 level or the detailed information about MMP-9 and clinicopathological features or survival rate was unavailable. Although we tried to contact all of the corresponding authors by e-mail to fill the data table, we were unable contact the authors within 6 weeks. Finally, including data presented here by our group, 27 studies were identified as eligible for this meta-analysis (Figure 1).

\section{Characteristics of eligible studies}

Except for the current study, a total of 26 published studies from 1999 to 2015 including 2637 NSCLC patients were enrolled in this meta-analysis (Table 2), which included 15 retrospective studies [1, 6, 7, 9-20], 9 observational studies [8, 21-28] and 2 prospective studies [5, 29]. Nineteen studies comprising 1964 subjects were conducted in Asia and 8 studies comprising 836 subjects were conducted in Western countries (Europe or USA). MMP-9 level was evaluated in the serum in 5 studies by ELISA, 21 studies used immunohistochemistry to detect MMP-9 and 1 study used a PCR method to assess the MMP-9 level in tumor tissue homogenate. None of the included patients received neo-adjuvant chemo- or radiotherapy pre-surgery. Furthermore, because the cut-off value for MMP-9 varied among studies, we defined the MMP-9 high expression group with respect to the original works.

\section{Correlation of MMP-9 expression and clinicopathological parameters}

The correlation between MMP-9 expression and overall gender, $\mathrm{T}$ category, $\mathrm{N}$ category, metastasis status and tumor stage was illustrated in Figure 2. Fifteen studies evaluated the association of MMP-9 expression and $\mathrm{T}$ category. The pooled RR was 0.83 (95\% CI: $0.73-$ $0.94)$ without heterogeneity $\left(\mathrm{I}^{2}=29.1 \%, \mathrm{p}=0.138\right)$. While the subgroup analysis was performed based on sample types (tissue or serum), we only found an increased risk of advanced T category with high MMP-9 expression in tissue specimens and not in serum (tissue $\mathrm{RR}=0.81,95 \% \mathrm{CI}: 0.72-0.92$; serum $\mathrm{RR}=0.93,95 \%$ CI: 0.51-1.68). Moreover, we evaluated the correlation between tumor stage and MMP-9 expression in twentytwo eligible studies, and the overall results indicate a positive association between high MMP-9 expression and advanced tumor stage $(\mathrm{RR}=0.72,95 \% \mathrm{CI}$ : 0.63-0.82) with heterogeneity $\left(\mathrm{I}^{2}=69.8 \%, \mathrm{p}=0.000\right)$. To explain the heterogeneity, we performed a subgroup analysis and found that high MMP-9 expression was also associated with advanced tumor stage only in tissue specimens and 
Table 1: Correlations between patients' backgrounds with the expression and activity of MMP-9 in 163 NSCLC patients

\begin{tabular}{|c|c|c|c|c|c|c|}
\hline \multirow[t]{2}{*}{ Characteristics } & \multicolumn{2}{|c|}{$\begin{array}{l}\text { No. of Cases with plasma MMP-9 } \\
\text { concentration of }\end{array}$} & \multicolumn{4}{|c|}{$\begin{array}{c}\text { No. of Cases with } \\
\text { plasma MMP-9 } \\
\text { activity of }\end{array}$} \\
\hline & $>67.08 \mathrm{ng} / \mathrm{ml}$ & $\leq 67.08 \mathrm{ng} / \mathrm{ml}$ & $\mathrm{p}$ & $>1.1$ & $\leq 1.1$ & $\mathrm{p}$ \\
\hline \multicolumn{7}{|l|}{ Gender } \\
\hline Male & 45 & 37 & 0.390 & 52 & 30 & 0.426 \\
\hline Female & 39 & 42 & & 46 & 35 & \\
\hline \multicolumn{7}{|l|}{ T stage } \\
\hline I & 34 & 52 & 0.066 & 33 & 53 & 0.0006 \\
\hline II-IV & 41 & 35 & & 49 & 27 & \\
\hline \multicolumn{7}{|c|}{ Lymph node metastasis } \\
\hline Yes & 47 & 44 & 0.700 & 49 & 42 & 0.507 \\
\hline No & 35 & 37 & & 35 & 37 & \\
\hline \multicolumn{7}{|c|}{ Distant metastasis } \\
\hline Yes & 30 & 25 & 0.199 & 33 & 22 & 0.002 \\
\hline No & 31 & 41 & & 23 & 49 & \\
\hline \multicolumn{7}{|l|}{ Tumor stage } \\
\hline I/II & 31 & 40 & 0.092 & 33 & 38 & 0.101 \\
\hline III/IV & 50 & 32 & & 49 & 33 & \\
\hline \multicolumn{7}{|l|}{ 3-year OS } \\
\hline Dead & 27 & 24 & 0.403 & 30 & 21 & 0.079 \\
\hline Live & 42 & 50 & & 40 & 52 & \\
\hline
\end{tabular}

223 potential relavant articles collected in Pubmed, Medline and ISI web of science

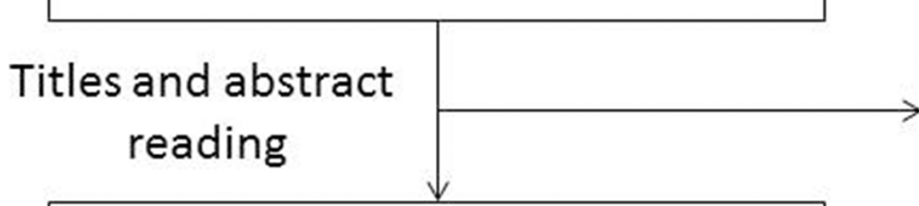

63 potential articles left for detail evaluation

\section{Full text reading}

26 potential articles left for detail evaluation
160 studies excluded: non-NSCLC, basic research studies, reviews or written in a language other than English or Chinese

37 studies excluded: MMP-9 cut-off value or related clinicopathological feature and survival data unavailable

Figure 1: Flow chart for selection of studies. 
Table 2: Main characteristics of the included studies in this meta-analysis

\begin{tabular}{|c|c|c|c|c|c|c|c|c|c|c|c|c|c|}
\hline No. & $\begin{array}{c}\text { Author, } \\
\text { year }\end{array}$ & Country & $\begin{array}{c}\text { No. of } \\
\text { patients }\end{array}$ & $\begin{array}{c}\text { Gender } \\
\text { (male/ } \\
\text { female) }\end{array}$ & $\begin{array}{l}\text { Specimen, } \\
\text { Method }\end{array}$ & $\begin{array}{l}\text { T stage } \\
(1 / 2-4)\end{array}$ & $\begin{array}{l}\text { N stage } \\
\text { (pos/neg) }\end{array}$ & $\begin{array}{c}\text { Distant } \\
\text { metastasis } \\
\text { (pos/neg) }\end{array}$ & $\begin{array}{c}\text { Tumor } \\
\text { Stage } \\
(1,2 / 3,4)\end{array}$ & $\begin{array}{c}\text { DFS } \\
\text { (relapse/ } \\
\text { free) }\end{array}$ & $\begin{array}{c}\text { 3-year OS } \\
\text { (dead/alive) }\end{array}$ & $\begin{array}{c}\text { 5-year OS } \\
\text { (dead/ } \\
\text { alive) }\end{array}$ & $\begin{array}{l}\text { NOS } \\
\text { score }\end{array}$ \\
\hline 1 & $\begin{array}{c}\text { Iizasa, } \\
1999\end{array}$ & Japan & 73 & $\begin{array}{c}\mathrm{H}(24 / 21) \\
\mathrm{L}(9 / 19)\end{array}$ & $\begin{array}{l}\text { Serum, } \\
\text { ELISA }\end{array}$ & NA & $\begin{array}{c}\mathrm{H}(22 / 24) \\
\mathrm{L}(11 / 16)\end{array}$ & $\begin{array}{l}\mathrm{H}(33 / 37) \\
\mathrm{L}(0 / 3)\end{array}$ & $\begin{array}{c}\mathrm{H}(19 / 23) \\
\mathrm{L}(14 / 17)\end{array}$ & NA & NA & NA & 6 \\
\hline 2 & $\begin{array}{l}\text { Cox, } \\
2000\end{array}$ & UK & 169 & $\begin{array}{l}\mathrm{H}(59 / 59) \\
\mathrm{L}(29 / 22)\end{array}$ & $\begin{array}{c}\text { Tissue, } \\
\text { IHC }\end{array}$ & $\begin{array}{c}\mathrm{H}(76 / 76) ; \\
\mathrm{L}(12 / 5)\end{array}$ & $\begin{array}{c}\mathrm{H}(41 / 47) \\
\mathrm{L}(47 / 34)\end{array}$ & NA & $\begin{array}{c}\mathrm{H}(63 / 67) \\
\mathrm{L}(25 / 14)\end{array}$ & NA & $\begin{array}{c}\mathrm{H}(49 / 32) \\
\mathrm{L}(29 / 52)\end{array}$ & $\begin{array}{l}\mathrm{H}(59 / 22) \\
\mathrm{L}(45 / 36)\end{array}$ & 8 \\
\hline 3 & $\begin{array}{c}\text { Zhao, } \\
2000\end{array}$ & China & 62 & $\begin{array}{l}\mathrm{H}(31 / 9) \\
\mathrm{L}(19 / 4)\end{array}$ & $\begin{array}{c}\text { Tissue, } \\
\text { IHC }\end{array}$ & $\begin{array}{l}\mathrm{H}(16 / 7) \\
\mathrm{L}(34 / 5)\end{array}$ & $\begin{array}{c}\mathrm{H}(11 / 27) \\
\mathrm{L}(23 / 1)\end{array}$ & NA & $\begin{array}{c}\mathrm{H}(26 / 11) \\
\mathrm{L}(24 / 1)\end{array}$ & NA & $\begin{array}{c}\mathrm{H}(23 / 27) \\
\mathrm{L}(0 / 12)\end{array}$ & $\begin{array}{l}\mathrm{H}(33 / 17) \\
\mathrm{L}(1 / 11)\end{array}$ & 7 \\
\hline 4 & $\begin{array}{l}\text { Shou, } \\
2001\end{array}$ & Japan & 119 & NA & $\begin{array}{c}\text { Tissue, } \\
\text { IHC }\end{array}$ & NA & NA & NA & NA & NA & $\begin{array}{c}\mathrm{H}(31 / 44) ; \\
\mathrm{L}(7 / 29)\end{array}$ & $\begin{array}{l}\mathrm{H}(44 / 31) ; \\
\mathrm{L}(11 / 25)\end{array}$ & 8 \\
\hline 5 & $\begin{array}{l}\text { Cao, } \\
2003\end{array}$ & China & 40 & NA & $\begin{array}{c}\text { Tissue, } \\
\text { IHC }\end{array}$ & NA & $\begin{array}{l}\mathrm{H}(6 / 6) ; \\
\mathrm{L}(1 / 27)\end{array}$ & NA & $\begin{array}{l}\mathrm{H}(9 / 5) \\
\mathrm{L}(24 / 2)\end{array}$ & NA & NA & NA & 5 \\
\hline 6 & $\begin{array}{c}\text { KAYA, } \\
2003\end{array}$ & Turkey & 35 & NA & $\begin{array}{l}\text { Serum, } \\
\text { ELISA }\end{array}$ & $\begin{array}{l}\mathrm{H}(5 / 16) \\
\mathrm{L}(6 / 8)\end{array}$ & $\begin{array}{c}\mathrm{H}(16 / 5) ; \\
\mathrm{L}(12 / 2)\end{array}$ & $\begin{array}{l}\mathrm{H}(11 / 10) \\
\mathrm{L}(4 / 10)\end{array}$ & $\begin{array}{l}\mathrm{H}(3 / 8) ; \\
\mathrm{L}(2 / 12)\end{array}$ & NA & NA & NA & 5 \\
\hline 7 & $\begin{array}{c}\text { Liang, } \\
2003\end{array}$ & China & 65 & NA & $\begin{array}{c}\text { Tissue, } \\
\text { IHC }\end{array}$ & $\begin{array}{c}\mathrm{H}(15 / 32) ; \\
\mathrm{L}(8 / 10)\end{array}$ & NA & $\begin{array}{l}\mathrm{H}(32 / 15) \\
\mathrm{L}(5 / 13)\end{array}$ & $\begin{array}{c}\mathrm{H}(23 / 24) \\
\mathrm{L}(16 / 2)\end{array}$ & NA & NA & NA & 6 \\
\hline 8 & $\begin{array}{c}\text { Sienel, } \\
2003\end{array}$ & Germany & 143 & $\begin{array}{c}\mathrm{H}(22 / 88) \\
\mathrm{L}(4 / 29)\end{array}$ & $\begin{array}{c}\text { Tissue, } \\
\text { IHC }\end{array}$ & $\begin{array}{c}\mathrm{H}(10 / 64) ; \\
\mathrm{L}(16 / 53)\end{array}$ & $\begin{array}{c}\mathrm{H}(39 / 35) \\
\mathrm{L}(38 / 31)\end{array}$ & NA & $\begin{array}{c}\mathrm{H}(14 / 49) \\
\mathrm{L}(8 / 46)\end{array}$ & NA & $\begin{array}{c}\mathrm{H}(71 / 35) \\
\mathrm{L}(10 / 14)\end{array}$ & $\begin{array}{l}\mathrm{H}(91 / 15) \\
\mathrm{L}(11 / 13)\end{array}$ & 8 \\
\hline 9 & $\begin{array}{l}\text { Wang, } \\
2003\end{array}$ & China & 104 & NA & $\begin{array}{c}\text { Tissue, } \\
\text { IHC }\end{array}$ & $\begin{array}{l}\mathrm{H}(57 / 18) ; \\
\mathrm{L}(21 / 8)\end{array}$ & $\begin{array}{l}\mathrm{H}(43 / 7) ; \\
\mathrm{L}(35 / 19)\end{array}$ & NA & $\begin{array}{l}\mathrm{H}(46 / 2) ; \\
\mathrm{L}(18 / 1)\end{array}$ & NA & NA & NA & 6 \\
\hline 10 & $\begin{array}{l}\text { Kim, } \\
2005\end{array}$ & USA & 74 & NA & $\begin{array}{c}\text { Tissue, } \\
\text { IHC }\end{array}$ & $\begin{array}{l}\mathrm{H}(48 / 23) ; \\
\mathrm{L}(3 / 0)\end{array}$ & $\begin{array}{c}\mathrm{H}(42 / 19) \\
\mathrm{L}(9 / 4)\end{array}$ & NA & NA & NA & $\begin{array}{c}\mathrm{H}(9 / 42) ; \\
\mathrm{L}(6 / 17)\end{array}$ & $\begin{array}{l}\mathrm{H}(15 / 36) ; \\
\mathrm{L}(7 / 16)\end{array}$ & 8 \\
\hline 11 & $\begin{array}{c}\text { Shimanuk, } \\
2005\end{array}$ & Japan & 61 & NA & $\begin{array}{l}\text { Serum, } \\
\text { ELISA }\end{array}$ & NA & NA & NA & NA & NA & $\begin{array}{c}\mathrm{H}(20 / 10) \\
\mathrm{L}(19 / 12)\end{array}$ & $\begin{array}{l}\mathrm{H}(21 / 9) ; \\
\mathrm{L}(20 / 10)\end{array}$ & 6 \\
\hline 12 & $\begin{array}{c}\text { Leinonen, } \\
2006\end{array}$ & Finland & 197 & NA & $\begin{array}{c}\text { Tissue, } \\
\text { IHC }\end{array}$ & $\begin{array}{c}\mathrm{H}(31 / 21) ; \\
\mathrm{L}(80 / 61)\end{array}$ & $\begin{array}{c}\mathrm{H}(29 / 31) \\
\mathrm{L}(82 / 51)\end{array}$ & NA & $\begin{array}{c}\mathrm{H}(42 / 49) \\
\mathrm{L}(51 / 23)\end{array}$ & $\begin{array}{l}\mathrm{H}(51 / 62) ; \\
\mathrm{L}(37 / 47)\end{array}$ & NA & $\begin{array}{l}\mathrm{H}(78 / 35) \\
\mathrm{L}(58 / 26)\end{array}$ & 7 \\
\hline 13 & $\begin{array}{l}\text { Wang, } \\
2005\end{array}$ & China & 64 & $\begin{array}{c}\mathrm{H}(33 / 12) \\
\mathrm{L}(16 / 7)\end{array}$ & $\begin{array}{c}\text { Tissue, } \\
\text { IHC }\end{array}$ & NA & $\begin{array}{l}\mathrm{H}(26 / 4) ; \\
\mathrm{L}(23 / 15)\end{array}$ & NA & $\begin{array}{c}\mathrm{H}(36 / 19) \\
\mathrm{L}(13 / 0)\end{array}$ & NA & NA & NA & 6 \\
\hline 14 & $\begin{array}{l}\text { Guo, } \\
2007\end{array}$ & China & 87 & NA & $\begin{array}{c}\text { Tissue, } \\
\text { IHC }\end{array}$ & NA & NA & $\begin{array}{c}\mathrm{H}(34 / 15) ; \\
\mathrm{L}(21 / 17)\end{array}$ & $\begin{array}{c}\mathrm{H}(20 / 18) \\
\mathrm{L}(35 / 14)\end{array}$ & $\begin{array}{l}\mathrm{H}(37 / 18) \\
\mathrm{L}(16 / 16)\end{array}$ & $\begin{array}{c}\mathrm{H}(15 / 40) \\
\mathrm{L}(7 / 25)\end{array}$ & $\begin{array}{l}\mathrm{H}(28 / 27) \\
\mathrm{L}(12 / 20)\end{array}$ & 8 \\
\hline 15 & $\begin{array}{c}\text { Iniesta, } \\
2007\end{array}$ & Spain & 92 & NA & $\begin{array}{l}\text { Tissue, } \\
\text { ELISA }\end{array}$ & NA & NA & NA & NA & $\begin{array}{l}\mathrm{H}(24 / 23) ; \\
\mathrm{L}(31 / 14)\end{array}$ & NA & NA & 5 \\
\hline 16 & $\begin{array}{l}\text { Chen, } \\
2008\end{array}$ & China & 41 & $\begin{array}{l}\mathrm{H}(16 / 9) \\
\mathrm{L}(11 / 5)\end{array}$ & $\begin{array}{c}\text { Tissue, } \\
\text { IHC }\end{array}$ & $\begin{array}{c}\mathrm{H}(10 / 11) ; \\
\mathrm{L}(17 / 6)\end{array}$ & $\begin{array}{c}\mathrm{H}(10 / 11) \\
\mathrm{L}(17 / 3)\end{array}$ & NA & $\begin{array}{c}\mathrm{H}(13 / 12) \\
\mathrm{L}(14 / 2)\end{array}$ & NA & $\begin{array}{l}\mathrm{H}(24 / 3) ; \\
\mathrm{L}(3 / 11)\end{array}$ & NA & 7 \\
\hline 17 & $\begin{array}{c}\text { Grossi, } \\
2008\end{array}$ & UK & 87 & NA & $\begin{array}{c}\text { Tissue, } \\
\text { IHC }\end{array}$ & NA & NA & NA & NA & NA & $\begin{array}{l}\mathrm{H}(34 / 9) ; \\
\mathrm{L}(30 / 14)\end{array}$ & $\begin{array}{l}\mathrm{H}(37 / 6) ; \\
\mathrm{L}(32 / 12)\end{array}$ & 7 \\
\hline 18 & $\begin{array}{l}\text { Lim, } \\
2010\end{array}$ & Korea & 41 & NA & $\begin{array}{c}\text { Tissue, } \\
\text { IHC }\end{array}$ & $\begin{array}{l}\mathrm{H}(12 / 21) \\
\mathrm{L}(3 / 5)\end{array}$ & $\begin{array}{c}\mathrm{H}(4 / 17) ; \\
\mathrm{L}(11 / 9)\end{array}$ & NA & $\begin{array}{l}\mathrm{H}(4 / 15) ; \\
\mathrm{L}(11 / 10)\end{array}$ & NA & NA & NA & 5 \\
\hline 19 & $\begin{array}{l}\text { Liu, } \\
2010\end{array}$ & China & 95 & $\begin{array}{c}\mathrm{H}(51 / 28) \\
\mathrm{L}(11 / 5)\end{array}$ & $\begin{array}{c}\text { Tissue, } \\
\text { IHC }\end{array}$ & $\begin{array}{l}\mathrm{H}(7 / 10) \\
\mathrm{L}(55 / 23)\end{array}$ & $\begin{array}{c}\mathrm{H}(28 / 23) \\
\mathrm{L}(34 / 10)\end{array}$ & $\begin{array}{l}\mathrm{H}(56 / 33) \\
\mathrm{L}(6 / 0)\end{array}$ & $\begin{array}{c}\mathrm{H}(31 / 26) \\
\mathrm{L}(31 / 7)\end{array}$ & NA & NA & NA & 7 \\
\hline 20 & $\begin{array}{r}\text { Shao, } \\
2011\end{array}$ & China & 146 & $\begin{array}{l}\mathrm{H}(59 / 36) \\
\mathrm{L}(30 / 21)\end{array}$ & $\begin{array}{c}\text { Tissue, } \\
\text { IHC }\end{array}$ & NA & NA & NA & NA & NA & $\begin{array}{c}\mathrm{H}(25 / 64) \\
\mathrm{L}(4 / 53)\end{array}$ & $\begin{array}{l}\mathrm{H}(25 / 64) ; \\
\mathrm{L}(5 / 52)\end{array}$ & 8 \\
\hline 21 & $\begin{array}{c}\mathrm{Li}, \\
2012\end{array}$ & China & 65 & NA & $\begin{array}{c}\text { Tissue, } \\
\text { IHC }\end{array}$ & NA & $\begin{array}{l}\mathrm{H}(17 / 9) ; \\
\mathrm{L}(17 / 22)\end{array}$ & $\begin{array}{c}\mathrm{H}(19 / 13) ; \\
\mathrm{L}(15 / 18)\end{array}$ & $\begin{array}{c}\mathrm{H}(23 / 12) \\
\mathrm{L}(11 / 19)\end{array}$ & NA & NA & NA & 6 \\
\hline 22 & $\begin{array}{c}\text { Schveigert, } \\
2013\end{array}$ & Poland & 20 & NA & $\begin{array}{c}\text { Tissue, } \\
\text { PCR }\end{array}$ & NA & $\begin{array}{c}\mathrm{H}(10 / 3) ; \\
\mathrm{L}(7 / 0)\end{array}$ & NA & $\begin{array}{c}\mathrm{H}(6 / 4) ; \\
\mathrm{L}(8 / 1)\end{array}$ & NA & NA & NA & 6 \\
\hline & & Poland & 19 & NA & $\begin{array}{l}\text { Serum, } \\
\text { PCR }\end{array}$ & NA & $\begin{array}{c}\mathrm{H}(9 / 4) ; \\
\mathrm{L}(6 / 1)\end{array}$ & NA & $\begin{array}{c}\mathrm{H}(7 / 3) ; \\
\mathrm{L}(9 / 0)\end{array}$ & NA & NA & NA & \\
\hline 23 & $\begin{array}{l}\text { Tang, } \\
2013\end{array}$ & China & 80 & $\begin{array}{c}\mathrm{H}(50 / 18) \\
\mathrm{L}(9 / 3)\end{array}$ & $\begin{array}{c}\text { Tissue, } \\
\text { IHC }\end{array}$ & $\begin{array}{c}\mathrm{H}(4 / 1) ; \\
\mathrm{L}(55 / 20)\end{array}$ & $\begin{array}{c}\mathrm{H}(56 / 16) \\
\mathrm{L}(3 / 5)\end{array}$ & NA & $\begin{array}{c}\mathrm{H}(15 / 13) \\
\mathrm{L}(44 / 8)\end{array}$ & NA & NA & NA & 5 \\
\hline
\end{tabular}




\begin{tabular}{|c|c|c|c|c|c|c|c|c|c|c|c|c|c|}
\hline No. & $\begin{array}{l}\text { Author, } \\
\text { year }\end{array}$ & Country & $\begin{array}{c}\text { No. of } \\
\text { patients }\end{array}$ & $\begin{array}{c}\text { Gender } \\
\text { (male/ } \\
\text { female) }\end{array}$ & $\begin{array}{l}\text { Specimen, } \\
\text { Method }\end{array}$ & $\begin{array}{l}\text { T stage } \\
(1 / 2-4)\end{array}$ & $\begin{array}{l}\text { N stage } \\
\text { (pos/neg) }\end{array}$ & $\begin{array}{c}\text { Distant } \\
\text { metastasis } \\
\text { (pos/neg) }\end{array}$ & $\begin{array}{c}\text { Tumor } \\
\text { Stage } \\
(\mathbf{1 , 2 / 3 , 4 )}\end{array}$ & $\begin{array}{c}\text { DFS } \\
\text { (relapse/ } \\
\text { free) }\end{array}$ & $\begin{array}{c}\text { 3-year OS } \\
\text { (dead/alive) }\end{array}$ & $\begin{array}{c}\text { 5-year OS } \\
\text { (dead/ } \\
\text { alive) }\end{array}$ & $\begin{array}{l}\text { NOS } \\
\text { score }\end{array}$ \\
\hline 24 & $\begin{array}{l}\text { Lee, } \\
2015\end{array}$ & Korea & 473 & $\begin{array}{c}\mathrm{H}(100 / 179) \\
\mathrm{L}(61 / 77)\end{array}$ & $\begin{array}{l}\text { Tissue, } \\
\text { IHC }\end{array}$ & $\begin{array}{l}\mathrm{H}(33 / 75) ; \\
\mathrm{L}(128 / 181)\end{array}$ & $\begin{array}{l}\mathrm{H}(53 / 52) \\
\mathrm{L}(108 / 204)\end{array}$ & NA & $\begin{array}{l}\mathrm{H}(128 / 228) ; \\
\mathrm{L}(33 / 28)\end{array}$ & $\begin{array}{l}\mathrm{H}(58 / 103) ; \\
\mathrm{L}(54 / 202)\end{array}$ & $\begin{array}{c}\mathrm{H}(33 / 128) ; \\
\mathrm{L}(48 / 218)\end{array}$ & $\begin{array}{l}\mathrm{H}(54 / 107) ; \\
\mathrm{L}(69 / 187)\end{array}$ & ; 8 \\
\hline 25 & $\begin{array}{l}\text { Liu, } \\
2015\end{array}$ & China & 87 & $\begin{array}{l}\mathrm{H}(24 / 18) \\
\mathrm{L}(28 / 17)\end{array}$ & $\begin{array}{c}\text { Tissue, } \\
\text { IHC }\end{array}$ & $\begin{array}{c}\mathrm{H}(30 / 29) \\
\mathrm{L}(22 / 6)\end{array}$ & $\begin{array}{c}\mathrm{H}(20 / 23) ; \\
\mathrm{L}(32 / 12)\end{array}$ & NA & $\begin{array}{l}\mathrm{H}(13 / 20) \\
\mathrm{L}(39 / 15)\end{array}$ & NA & NA & NA & 6 \\
\hline 26 & $\begin{array}{l}\mathrm{Su}, \\
2015\end{array}$ & China & 98 & $\begin{array}{l}\mathrm{H}(41 / 12) \\
\mathrm{L}(28 / 17)\end{array}$ & $\begin{array}{c}\text { Tissue, } \\
\text { IHC }\end{array}$ & NA & $\begin{array}{c}\mathrm{H}(23 / 14) \\
\mathrm{L}(46 / 15)\end{array}$ & $\begin{array}{c}\mathrm{H}(46 / 24) \\
\mathrm{L}(23 / 5)\end{array}$ & $\begin{array}{l}\mathrm{H}(27 / 15) ; \\
\mathrm{L}(42 / 14)\end{array}$ & $\begin{array}{l}\mathrm{H}(54 / 15) ; \\
\mathrm{L}(18 / 11)\end{array}$ & $\begin{array}{c}\mathrm{H}(50 / 19) \\
\mathrm{L}(14 / 15)\end{array}$ & $\begin{array}{l}\mathrm{H}(54 / 15) ; \\
\mathrm{L}(18 / 11)\end{array}$ & 8 \\
\hline 27 & $\begin{array}{c}\text { Gong, } \\
2015\end{array}$ & China & 163 & $\begin{array}{l}\mathrm{H}(49 / 33) \\
\mathrm{L}(46 / 37)\end{array}$ & $\begin{array}{l}\text { Serum, } \\
\text { ELISA }\end{array}$ & $\begin{array}{l}\mathrm{H}(52 / 35) \\
\mathrm{L}(41 / 35)\end{array}$ & $\begin{array}{l}\mathrm{H}(58 / 33) \\
\mathrm{L}(35 / 37)\end{array}$ & $\begin{array}{l}\mathrm{H}(35 / 20) \\
\mathrm{L}(58 / 50)\end{array}$ & $\begin{array}{l}\mathrm{H}(40 / 31) ; \\
\mathrm{L}(53 / 39)\end{array}$ & NA & $\begin{array}{c}\mathrm{H}(32 / 61) \\
\mathrm{L}(19 / 51)\end{array}$ & NA & 7 \\
\hline
\end{tabular}

H: high expression; L: low expression; NA: not available; IHC: immunohistochemistry; NOS, Newcastle-Ottawa Quality Assessment Scale.

not serum (tissue $\mathrm{RR}=0.69,95 \% \mathrm{CI}: 0.60-0.80$, serum $\mathrm{RR}=0.92,95 \%$ CI: 0.75-1.14).

However, the results did not reveal a significant relationship between overall MMP-9 expression with either lymph node or distant organ metastasis ( $\mathrm{N}$ category $\mathrm{RR}=0.93,95 \% \mathrm{CI}: 0.78-1.10 ; \mathrm{M}$ category $\mathrm{RR}=1.12$, 95\%CI: $0.85-1.48)$. Similar results were also found in the sub-group analysis ( $\mathrm{N}$ category tissue $\mathrm{RR}=0.91,95 \%$ CI: 0.74-1.11, serum RR $=1.02,95 \%$ CI: $0.79-1.31 ; \mathrm{M}$ category tissue $\mathrm{RR}=1.05,95 \% \mathrm{CI}$ : $0.85-1.48$, serum $\mathrm{RR}=1.24,95 \%$ CI: 0.96-1.60). Gender was also not a parameter that correlated with MMP-9 expression either in overall or subgroup analysis based on sample types $(\mathrm{RR}=$ 1.0, 95\% CI: 0.91-1.09, Supplementary Figure S2).

\section{Impact of MMP-9 expression on overall survival and disease-free survival of NSCLC}

The 5-year DFS data were extracted from 5 articles all studying tissue specimens (Figure 3), and the pooled analysis found that an increased expression of MMP-9 did not correlate with disease progression (pooled $R R=1.15$, 95\% CI: 0.89-1.48). Then, we assessed whether the MMP-9 level was associated with OS (Figure 3). The 3-year OS rate of the MMP-9 high and low groups was 55.3\% (514/930) and $62.9 \%(1037 / 1649)$, respectively, while the 5-year OS was $41.6 \%$ (382/923) and 49.2\% (803/1631), respectively. Our analysis revealed that MMP-9 significantly indicated poor overall survival in both 3-year and 5-year OS (pooled 3 -year $\mathrm{RR}=1.31,95 \%$ CI: 1.18-1.45; pooled 5-year RR $=$ 1.32, 95\% CI: 1.19-1.48). Because there was only one study with serum samples that provided information on the 5 -year OS rate, the stratified analysis was only performed for the 3 -year OS. It was interesting that the subgroup analysis again found that high MMP-9 expression in tissue but not serum indicated a worse prognosis (tissue group $\mathrm{RR}=1.33,95 \%$ CI: 1.18-1.50; serum group $\mathrm{RR}=1.15,95 \% \mathrm{CI}$ : 0.90-1.46).

\section{Publication bias}

Begg's and Egger's tests were both performed to determine the publication bias based on clinicopathological and survival parameters. The funnel plots were almost symmetrical and did not indicate any significant biases among the studies.

\section{DISCUSSION}

Here we present a meta-analysis based on a large pool of studies (including 16 retrospective studies, 9 observational studies and 2 prospective studies) that evaluated the clinical relevance and prognostic value of MMP-9 in NSCLC patients. One systematic review regarding MMP-9 in NSCLC was published in 2012 and concluded that MMP-9 is associated with poor prognosis [30]. However, because of the limited information, the previous meta-analysis was confined to studies with immunohistochemistry assay to detect the MMP-9 expression in the tissue. Because the significance of the MMP-9 level in NSCLC still remains controversial, we constructed this meta-analysis and tried to illuminate this issue.

MMP-9 is secreted by various cells in an inactivated form as a $10 \mathrm{kDa}$ propeptide, which could be activated by other MMPs or tissue plasminogen activator (tPA)plasmin system, due to its biological function of cleaving gelatin, which promotes malignant cell motility $[3,4]$, MMP-9 was regarded as an important prognostic marker and therapeutic target of cancer in many studies. The biology of MMP-9 was comprehensively reviewed by Vandooren et al. [2]. In brief, basic studies have revealed that a high expression of MMP-9 is positively associated with the aggressiveness of malignant cells in solid tumors. Except for its well-known function of degrading the extracellular matrix, in vivo studies in MMP-9 deficient mice found that tumor metastasis was enhanced by implanting MMP-9 expression in the bone marrow, which could promote angiogenesis to facilitate cancer cell migration. Additionally, MMP-9 could be derived from stromal cells, such as inflammatory cells and fibroblasts $[31,32]$. Furthermore, although a soluble enzyme, MMP9 could also bind to CD44 to activate the TGF- $\beta$ pathway to enhance angiogenesis and epithelial to mesenchymal transition [33, 34], and it could also down-regulate the expression of E-cadherin as a transcriptional factor [35]. 
Although all of the above mentioned evidence strongly supports the fact that MMP-9 could potentiate cancer aggressiveness, there still remains controversy among the clinical observational studies. In our study, 163 serum samples of NSCLC patients were collected and the circulating MMP-9 expression was assessed. Our retrospective analysis did not find any significant correlation between total serum MMP-9 expression and clinicopathological features or survival. Because the activity of MMP-9 could not be detected by ELISA, a gelatin zymography assay was performed, and high activity of MMP-9 was a risk factor of advanced tumor stage and distant metastasis, which is concordant with El-Badrawy et al.'s report [36]. In addition to our retrospective analysis, we also conducted a meta-analysis to address the prognostic value of MMP-9 in NSCLC; however, neither of the included studies determined its activity in tissue or serum. Our systematic analysis revealed that MMP-9 expression in tumor tissue was

A
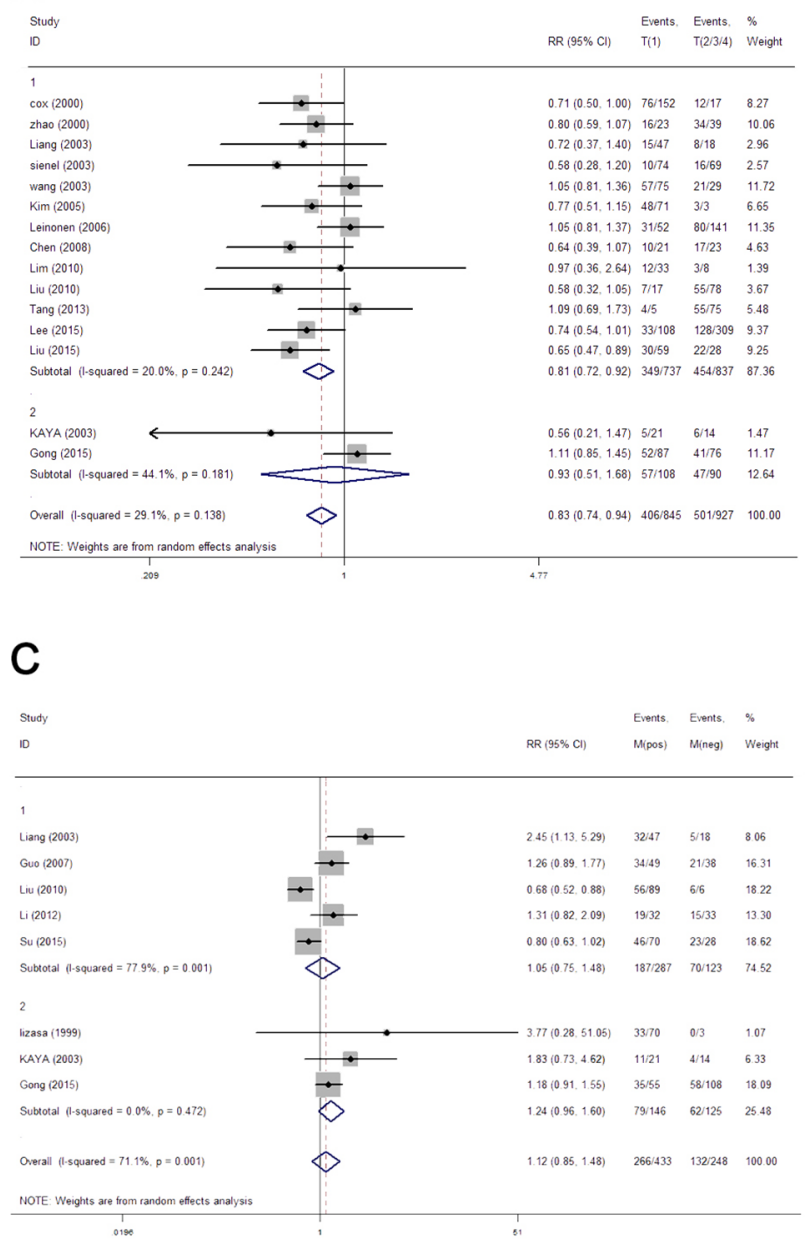

positively related to $\mathrm{T}$ category, tumor stage, and 3-year and 5-year OS rate while a high level of MMP-9 in the serum was not associated with any of these parameters.

The increment of circulating MMP-9 was released by tumor cells or stromal cells, and its activity could be downregulated by many extracellular factors, such as MMP$1,3,7,10,26$, trypsin-2 and neutrophil elastase [37], among them, the tissue inhibitors of metalloproteinases 1 (TIMP1) is the most important endogenous inhibitor against MMP-9. TIMP1 belongs to a family of proteins that naturally inhibit MMPs, which consists of four members (TIMP1, TIMP2, TIMP3, and TIMP4). In fact, several studies revealed that TIMP1 not only blocks the cleavage effect of MMP9 extracellularly but also inhibits the membrane-protein shedding process and cell signal regulatory effect of MMP9 [38-40]. Although the anti-MMP-9 behavior led TIMP1 to be considered as a tumor suppress gene initially, later, researchers found that TIMP1 also functions independently of MMP-9 to promote tumor growth and inhibit apoptosis
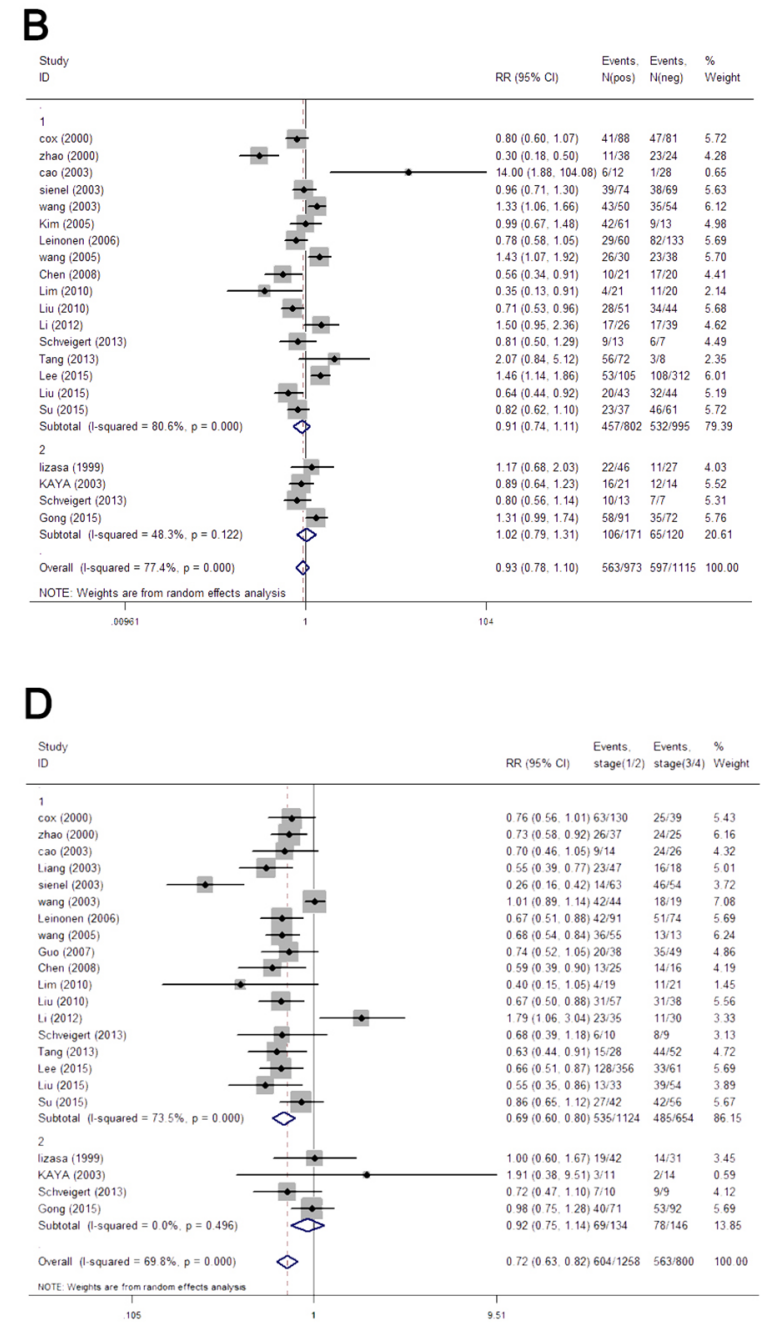

Figure 2: The forest plot of RRs was assessed for association between MMP-9 and clinicopathological features, including T category A. lymph node metastasis B. distant organ metastasis C. and tumor grade D. Each result was shown by the RR with $95 \%$ CIs (according to the fixed model). 

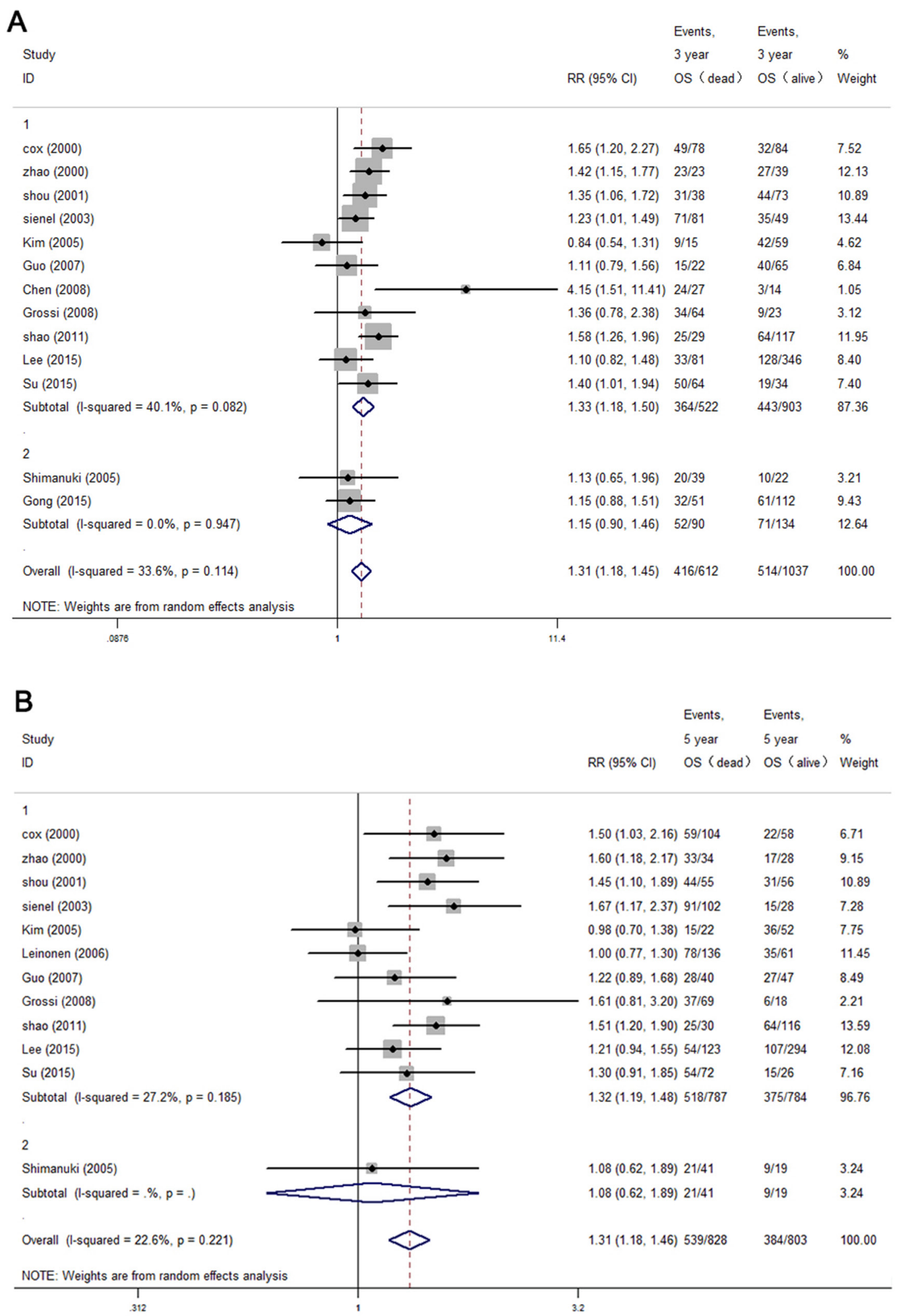

Figure 3: The forest plot of RRs was assessed for association between MMP-9 expression and 3-year overall survival A. 5-year overall survival B. Each result was shown by the RR with 95\% CIs (according to the fixed model or random model). 
[41]. TIMP1 expression was increased in solid tumors, such as lung cancer, breast cancer and colorectal cancer, and was acknowledged as a risk factor of poor outcome [42-44]. Its high expression not only impedes the activity of MMP-9 but also potentiates the aggressiveness of malignant cells. Based on our own data and meta-analysis here, the activity of serum MMP-9 was associated with tumor stage and metastasis status, but its total expression in serum was not related to clinicopathological parameters or survival. Therefore, the activity of circulating MMP-9 may not be proportional to the amount detected by ELISA. Weng et al. found that MMP-9 activity was reduced in lung cancer tissue [45], which could also be proof of this corollary.

This meta-analysis is subject to a few limitations. First, almost $75 \%$ of patients were from studies in Asia, which may have induced bias; second, the number of studies with serum samples is relatively small, and the survival information was unavailable for most of them; third, although subgroup studies in stratified analysis applied a consistent method to determine the expression of MMP-9, the criteria still varied among individual studies, which may be attributed to different antibodies and the influence of pathologists; fourth, our meta-analysis is based on published literature, and thus, some information was missed and individual patient data were unattainable, which could decrease the accuracy of the results. In spite of these limitations, our meta-analysis result revealed that high MMP-9 expression in tumor tissue but not serum could be an implication of advanced tumor stage and poor prognosis of NSCLC. It should be prudent to detect serum MMP-9 expression as a prognostic factor in the future, and a parallel study with a large number of subjects is needed in the future to compare the clinical significance of total expression of tissue MMP-9 and the activity of MMP-9 both in tumor tissue and serum.

\section{MATERIALS AND METHODS}

\section{Subjects and specimen collection}

A total of 163 patients with NSCLC, including 76 squamous cell carcinoma, 79 adenocarcinoma and 8 large cell carcinoma, of the Wenzhou Medical College Affiliated Cixi People's Hospital (Zhejiang province, China) were included in this study. For all of the patients, the diagnosis was confirmed by histological examination of either biopsy or cytologic specimen. Informed consent was obtained from each patient, and also permitted by the ethic committee of Wenzhou Medical College Affiliated Cixi People's Hospital. Venous blood samples were collected from all of the patients via routine venipuncture. The blood samples were obtained using an EDTA anti-coagulant tube, immediately centrifuged and the serum was stored at$80^{\circ} \mathrm{C}$. The survival information was available in 143 patients, while the rest were lost to follow-up.

\section{Measurement of MMP-9 by enzyme-linked immunosorbent assay (ELISA)}

The expression of MMP-9 in the serum was measured using a human MMP-9 ELISA kit (R\&D Systems, Abingdon, UK) by following the manufacturer's instruction strictly, and all of the samples were measured in triplicate.

\section{Measurement of MMP-9 by gelatin zymography}

MMP-9 activity in serum was detected by gelatin zymography as described previously [36]. Briefly, the protein concentration of the serum samples was determined using the Bradford protein assay. Then, 20 $\mathrm{mg}$ of total protein was electrophoresed on a $10 \%$ sodium dodecyl sulfate polyacrylamide gel at room temperature for $1 \mathrm{~h}$. After electrophoresis, the gels were treated with Triton X-100 for 30 minutes at room temperature followed by incubation in a reaction buffer containing $50 \mathrm{mM}$ Tris (pH 7.4), $5 \mathrm{mM} \mathrm{CaCl}$, and $150 \mathrm{mM} \mathrm{NaCl}$ for 24 hours at $37^{\circ} \mathrm{C}$, then stained with Coomassie blue. The activity of MMP-9 was considered a band at $78 \mathrm{kDa}$, and MMP-9 activity was analyzed by NIH image software (v1.62). The activity of MMP-9 in the samples was determined as the percentage ratio between the intensity of the gel analytic bands in the samples in relation to the standard MMP-9 (92 kDa) (NBP1-99195-Novus Biologicals).

\section{Literature search strategy}

We performed a comprehensive literature search of Medline and ISI Web of Knowledge up to November of 2015 with regard to the prognostic significance of MMP-9 in NSCLC. Search items included "MMP-9" or "matrix metallopreoteinases-9" and "NSCLC" or "non-small cell lung cancer." The titles and abstracts of publications identified by the search were examined manually to exclude reviews, letters, basic research and other irrelevant studies.

\section{Eligibility criteria}

The studies in this meta-analysis included both prospective or retrospective studies, and the studies were selected if they met the following criteria: (a) focused on NSCLC and more than 20 patients, (b) they defined MMP-9 expression in the tumor specimen or serum, (c) clear analysis of correlations between MMP-9 expression and clinicopathological features or survival outcomes (overall or disease free survival), and (d) the studies were published in English or Chinese.

To control for the quality of this meta-analysis, all of the enrolled studies were examined with seven key points provided by the Dutch Cochrane Centre: (a) a clear definition of study population and country of origin, (b) a clear definition of the type of carcinoma, (c) a clear 
definition of the study design, (d) a clear definition of the outcome assessment, (e) a clear definition of the cut-off of MMP-9 expression, (f) a clear definition of the method of MMP-9 assessment and (g) a sufficient time for follow-up.

\section{Data extraction}

All of the data were extracted independently by two reviewers. The following data were extracted using a standardized method: author's name, publication year, country, number of patients, detection method, type of specimen, cut-off value for MMP-9, T category, $\mathrm{N}$ category, distant metastasis, DFS rate and OS rate. For studies that provided OS or PFS with a Kaplan-Meier curve, GetData Graph Digitizer 2.24 software (http:// getdata-graph-digitizer.com/) was used to digitize and extract the data from the Kaplan-Meier curves. We also tried our best to collect the missing information by emailing the corresponding author.

\section{Statistical analysis}

For the data provided by our group, the results are presented as the mean \pm standard error of the mean, and all of the data were analyzed by the Mann-Whitney rank sum test between groups with GraphPad Prism 6.0. For the meta-analysis, the extracted data were analyzed with guidelines proposed by the Meta-Analysis of Observational Studies in Epidemiology group. Relative risk (RR) with a 95\% confidence interval (95\% CI) was determined with Review Manager 4.2. The heterogeneity among studies was measured by $\mathrm{Q}$ and $I^{2}$ tests. A fixed or random model was used depending on the heterogeneity analysis. The potential for publication bias was also evaluated using the Begg rank correlation method and the Egger weighted regression method (Stata11.0 software). A $P$ value $<0.05$ was considered statistically significant. All $P$ values are two-tailed.

\section{ACKNOWLEDGMENTS}

This work was supported by the Natural Science Foundation of China (grant number 81502463), Natural Science Foundation of Zhejiang Province (grant number LY12H13002, LY15H160053, LQ15H070004 ), project of Zhejiang Traditional Chinese Medicine Administration (Grant No.2012ZZ012), project of Zhejiang medical health science plan (Grant No.2015RCB026), project of Zhejiang traditional Chinese medicine research (Grant No. 2013ZB115, 2015ZB107, 2016ZB115) and Science and Technology foundation of Cixi (CN2013013).

\section{CONFLICTS OF INTEREST}

No potential conflicts of interest were disclosed.

\section{REFERENCES}

1. Lee CY, Shim HS, Lee S, Lee JG, Kim DJ and Chung KY. Prognostic effect of matrix metalloproteinase-9 in patients with resected Non small cell lung cancer. Journal of cardiothoracic surgery. 2015; 10:44.

2. Vandooren J, Van den Steen PE and Opdenakker G. Biochemistry and molecular biology of gelatinase B or matrix metalloproteinase-9 (MMP-9): the next decade. Critical reviews in biochemistry and molecular biology. 2013; 48:222-272.

3. Shi M, Cao M, Song J, Liu Q, Li H, Meng F, Pan Z, Bai $\mathrm{J}$ and Zheng J. PinX1 inhibits the invasion and metastasis of human breast cancer via suppressing NF-kappaB/ MMP-9 signaling pathway. Molecular cancer. 2015; 14:66.

4. Xia Y, Lian S, Khoi PN, Yoon HJ, Joo YE, Chay KO, Kim KK and Do Jung Y. Chrysin inhibits tumor promoterinduced MMP-9 expression by blocking AP-1 via suppression of ERK and JNK pathways in gastric cancer cells. PloS one. 2015; 10:e0124007.

5. Kim SJ, Rabbani ZN, Dewhirst MW, Vujaskovic Z, Vollmer RT, Schreiber EG, Oosterwijk E and Kelley MJ. Expression of HIF-1alpha, CA IX, VEGF, and MMP-9 in surgically resected non-small cell lung cancer. Lung cancer. 2005; 49:325-335.

6. Shimanuki Y, Takahashi K, Cui R, Hori S, Takahashi F, Miyamoto H and Fukurchi Y. Role of serum vascular endothelial growth factor in the prediction of angiogenesis and prognosis for non-small cell lung cancer. Lung. 2005; 183:29-42.

7. Leinonen T, Pirinen R, Bohm J, Johansson R, Ropponen K and Kosma VM. Expression of matrix metalloproteinases 7 and 9 in non-small cell lung cancer. Relation to clinicopathological factors, beta-catenin and prognosis. Lung cancer. 2006; 51:313-321.

8. Kaya A, Gulbay BE, Gurkan OU, Celik G, Savas $\mathrm{H}$ and Savas I. Elevated levels of circulating matrix metalloproteinase-9 in non-small cell lung cancer patients. Tuberkuloz ve toraks. 2003; 51:380-384.

9. Cox G, Jones JL and O'Byrne KJ. Matrix metalloproteinase 9 and the epidermal growth factor signal pathway in operable non-small cell lung cancer. Clinical cancer research. 2000; 6:2349-2355.

10. Zhao Z, Zhang M and Ru G. [Expression of MMP-2 and MMP-9 in non-small-cell lung cancer and their prognostic value.]. Zhongguo fei ai za $\mathrm{zhi}=$ Chinese journal of lung cancer. 2000; 3:107-110.

11. Shou Y, Hirano T, Gong Y, Kato Y, Yoshida K, Ohira T, Ikeda N, Konaka C, Ebihara Y, Zhao F and Kato $H$. Influence of angiogenetic factors and matrix metalloproteinases upon tumour progression in nonsmall-cell lung cancer. British journal of cancer. 2001; 85:1706-1712. 
12. Liang J, Lin M, Xie M and Liu X. [Expressions of matrix metalloproteinase 9 and tissue inhibitor of metalloproteinase 1 and their correlation with metastasis and prognosis in lung cancer]. Zhongguo fei ai za zhi $=$ Chinese journal of lung cancer. 2003; 6:46-50.

13. Guo CB, Wang S, Deng C, Zhang DL, Wang FL and Jin XQ. Relationship between matrix metalloproteinase 2 and lung cancer progression. Molecular diagnosis \& therapy. 2007; 11:183-192.

14. Iniesta P, Moran A, De Juan C, Gomez A, Hernando F, Garcia-Aranda C, Frias C, Diaz-Lopez A, RodriguezJimenez FJ, Balibrea JL and Benito M. Biological and clinical significance of MMP-2, MMP-9, TIMP-1 and TIMP-2 in non-small cell lung cancer. Oncology reports. 2007; 17:217-223.

15. Chen XL, Wang LC, Zhang WG, Chen XY and Sun ZM. [Correlations of S100A4 and MMP9 expressions to infiltration, metastasis and prognosis of non-small cell lung cancer]. Nan fang yi ke da xue xue bao = Journal of Southern Medical University. 2008; 28:1254-1258.

16. Grossi F, Spizzo R, Bordo D, Cacitti V, Valent F, Rossetto C, Follador A, Di Terlizzi S, Aita M, Morelli A, Fasola G, Consiglieri C, Ceschia T, Beltrami CA and Belvedere O. Prognostic stratification of stage IIIA pN2 non-small cell lung cancer by hierarchical clustering analysis of tissue microarray immunostaining data: an Alpe Adria Thoracic Oncology Multidisciplinary Group study (ATOM 014). Journal of thoracic oncology. 2010; 5:1354-1360.

17. Lim BJ, Jung SS, Choi SY and Lee CS. Expression of metastasis-associated molecules in non-small cell lung cancer and their prognostic significance. Molecular medicine reports. 2010; 3:43-49.

18. Shao W, Wang W, Xiong XG, Cao C, Yan TD, Chen G, Chen H, Yin W, Liu J, Gu Y, Mo M and He J. Prognostic impact of MMP-2 and MMP-9 expression in pathologic stage IA non-small cell lung cancer. Journal of surgical oncology. 2011; 104:841-846.

19. Schveigert D, Cicenas S, Bruzas S, Samalavicius NE, Gudleviciene $Z$ and Didziapetriene J. The value of MMP-9 for breast and non-small cell lung cancer patients' survival. Advances in medical sciences. 2013; 58:73-82.

20. Su CY, Liu YP, Yang CJ, Lin YF, Chiou J, Chi LH, Lee JJ, Wu AT, Lu PJ, Huang MS and Hsiao M. Plasminogen Activator Inhibitor-2 Plays a Leading Prognostic Role among Protease Families in Non-Small Cell Lung Cancer. PloS one. 2015; 10:e0133411.

21. Iizasa T, Fujisawa T, Suzuki M, Motohashi S, Yasufuku K, Yasukawa T, Baba M and Shiba M. Elevated levels of circulating plasma matrix metalloproteinase 9 in non-small cell lung cancer patients. Clinical cancer research. 1999; 5:149-153.

22. Cao L, Yang $\mathrm{H}$ and $\mathrm{Hu}$ C. [The expression and its clinical significance of MMP-2 and MMP-9 in non-small cell lung cancer]. Zhongguo fei ai za zhi $=$ Chinese journal of lung cancer. 2003; 6:484-487.

23. Wang $\mathrm{X}$, Yang J, Ma Y, Zheng H, Cheng B, Zheng $\mathrm{H}$ and $\mathrm{Zhu} \mathrm{C}$. [Expression and significance of matrix metalloproteinases and their tissue inhibitors in the infiltration and metastasis of lung cancer]. Zhongguo fei ai za zhi $=$ Chinese journal of lung cancer. 2003; 6:278-282.

24. Wang J, Miao LJ, Wu YM, Wu YJ and Wang XC. [Expression of AKT2, cyclin D1, and MMP-9 and their correlations to clinicopathologic features of non-small cell lung cancer]. Ai zheng $=$ Aizheng $=$ Chinese journal of cancer. 2006; 25:69-72.

25. Liu Z, Xu S, Xiao N, Song $\mathrm{C}$, Zhang $\mathrm{H}$ and Li F. [Overexpression of IL-8 and MMP-9 confer high malignant phenotype in patients with non-small cell lung cancer]. Zhongguo fei ai za zhi $=$ Chinese journal of lung cancer. 2010; 13:795-802.

26. Li RJ, Zhao LJ, Zhan ZL, Lu X, Gong LL and Wang P. [Significance of expression of chemokine receptor and matrix metalloproteinase in small cell lung cancer]. Zhonghua yi xue za zhi. 2012; 92:532-535.

27. Tang C, Luo D, Yang H, Wang Q, Zhang R, Liu G and Zhou X. Expression of SHP2 and related markers in nonsmall cell lung cancer: a tissue microarray study of 80 cases. Applied immunohistochemistry \& molecular morphology. 2013; 21:386-394.

28. Liu F and Zhu L. [Expression of adiponectin in non-small cell lung cancer and its relationship with MMP-9 and angiogenesis]. Zhong nan da xue xue bao Yi xue ban = Journal of Central South University Medical sciences. 2015; 40:579-584.

29. Sienel W, Hellers J, Morresi-Hauf A, Lichtinghagen R, Mutschler W, Jochum M, Klein C, Passlick B and Pantel K. Prognostic impact of matrix metalloproteinase-9 in operable non-small cell lung cancer. International journal of cancer. 2003; 103:647-651.

30. Peng WJ, Zhang JQ, Wang BX, Pan HF, Lu MM and Wang J. Prognostic value of matrix metalloproteinase 9 expression in patients with non-small cell lung cancer. Clinica chimica acta. 2012; 413:1121-1126.

31. Acuff HB, Sinnamon M, Fingleton B, Boone B, Levy SE, Chen X, Pozzi A, Carbone DP, Schwartz DR, Moin $\mathrm{K}$, Sloane BF and Matrisian LM. Analysis of host- and tumor-derived proteinases using a custom dual species microarray reveals a protective role for stromal matrix metalloproteinase-12 in non-small cell lung cancer. Cancer research. 2006; 66:7968-7975.

32. Itoh T, Tanioka M, Matsuda H, Nishimoto H, Yoshioka T, Suzuki R and Uehira M. Experimental metastasis is suppressed in MMP-9-deficient mice. Clinical \& experimental metastasis. 1999; 17:177-181.

33. Yu Q and Stamenkovic I. Cell surface-localized matrix metalloproteinase-9 proteolytically activates TGF-beta and promotes tumor invasion and angiogenesis. Genes \& development. 2000; 14:163-176. 
34. Dufour A, Sampson NS, Zucker S and Cao J. Role of the hemopexin domain of matrix metalloproteinases in cell migration. Journal of cellular physiology. 2008; 217:643-651.

35. Wang JR, Gan WJ, Li XM, Zhao YY, Li Y, Lu XX, $\mathrm{Li} \mathrm{JM}$ and $\mathrm{Wu} \mathrm{H}$. Orphan nuclear receptor Nur77 promotes colorectal cancer invasion and metastasis by regulating MMP-9 and E-cadherin. Carcinogenesis. 2014; 35:2474-2484.

36. El-Badrawy MK, Yousef AM, Shaalan D and Elsamanoudy AZ. Matrix metalloproteinase-9 expression in lung cancer patients and its relation to serum mmp-9 activity, pathologic type, and prognosis. Journal of bronchology \& interventional pulmonology. 2014; 21:327-334.

37. Van den Steen PE, Dubois B, Nelissen I, Rudd PM, Dwek RA and Opdenakker G. Biochemistry and molecular biology of gelatinase B or matrix metalloproteinase-9 (MMP-9). Critical reviews in biochemistry and molecular biology. 2002; 37:375-536.

38. Stetler-Stevenson WG. Tissue inhibitors of metalloproteinases in cell signaling: metalloproteinaseindependent biological activities. Science signaling. 2008; 1:re6.

39. Brew $\mathrm{K}$ and Nagase $\mathrm{H}$. The tissue inhibitors of metalloproteinases (TIMPs): an ancient family with structural and functional diversity. Biochimica et biophysica acta. 2010; 1803:55-71.

40. Hornebeck W, Lambert E, Petitfrere E and Bernard P. Beneficial and detrimental influences of tissue inhibitor of metalloproteinase-1 (TIMP-1) in tumor progression. Biochimie. 2005; 87:377-383.

41. Ries C. Cytokine functions of TIMP-1. Cellular and molecular life sciences. 2014; 71:659-672.

42. Zhu D, Zha X, Hu M, Tao A, Zhou H, Zhou X and Sun Y. High expression of TIMP-1 in human breast cancer tissues is a predictive of resistance to paclitaxel-based chemotherapy. Medical oncology. 2012; 29:3207-3215.

43. Pesta M, Kulda V, Kucera R, Pesek M, Vrzalova J, Liska V, Pecen L, Treska V, Safranek J, Prazakova M, Vycital O, Bruha J, Holubec L and Topolcan O. Prognostic significance of TIMP-1 in non-small cell lung cancer. Anticancer research. 2011; 31:4031-4038.

44. Jensen SA, Vainer B, Bartels A, Brunner N and Sorensen JB. Expression of matrix metalloproteinase 9 (MMP-9) and tissue inhibitor of metalloproteinases 1 (TIMP-1) by colorectal cancer cells and adjacent stroma cells-associations with histopathology and patients outcome. European journal of cancer. 2010; 46:3233-3242.

45. Weng Y, Cai M, Zhu J, Geng J, Zhu K, Jin X and Ding W. Matrix metalloproteinase activity in early-stage lung cancer. Onkologie. 2013; 36:256-259. 